\title{
ON THE INTESTINAL INTRINSIC REFLEXES
}

\author{
TAKESI HUKUHARA, MATUYOSI YAMAGAMI \\ AND SOSOGU NAKAYAMA* \\ Department of Physiology, Okayama University Medical School, Okayama, Japan
}

Hukuhara studied the normal movements of the small intestine by means of the abdominal window-method and concluded that the intestinal movements consisted essentially of a kind of the contraction wave, although these movements showed apparently manifold aspects $(11,12,14)$. The intestinal movements are regulated in situ reflexively via the extrinsic and intrinsic nerves. As regard to the effect of the extrinsic reflex of the small intestine only an inhibitory one was observed $(10,18,20,22,23)$, while the effects of the intrinsic reflex have been of a complicated character as shown in the following historical survey.

Nothnagel (19) seems to be the first worker, who presumed the existence of the intrinsic reflex. He showed that the application of crystals of sodium chloride to the intestinal wall in cats and rabbits produced a constriction ring propagated oral about $1 \mathrm{~cm}$. Lüderitz (16) noticed then that the distension of a balloon introduced into the intestinal lumen of dogs caused the ascending contraction wave. In 1899 Bayliss and Starling (4) investigated the effects of pinching of the intestinal wall of dogs upon the movements of the denervated small intestine, and found that the rhythmic contractions were inhibited on the anal side of the pinched region, whereas on the oral side they became more powerful than before pinching. They remarked, however, that the intestinal motility was occasionally inhibited on both sides of the pinched region. The results obtained by the above mentioned authors were confirmed by Magnus (17), and Langley and Magnus (15). In 1936 Hukuhara et al. (13) studied further in detail the phenomena mentioned above in dogs. According to them, when the duodenum was pinched strongly, at first the extrasystolic contraction waves propagated from the pinched region to the oral as well as to the anal direction and then the duodenal movements were almost completely inhibited on both sides of the stimulated region, while the stimulated region itself fell into a tonic contraction. In the mean while the tonically contracted region relaxed moderately and began to pulsate, giving rise to propagated waves rhythmically orad as well as anad, although the ascending waves were far more powerful than the descending. The more the tonically contracted region relaxed, the weaker the ascending waves became till they were at last overcome by the normal waves which originated from the pace maker. Recently Bozler (7) observed that distension of the intestinal wall or stroking the mucosa with a blunt instrument

Received for publication October 25, 1957.

* 福原 武, 山上松義, 中山 沃 
increased the strength of the rhythmic contractions on the oral side or initiated the ascending contraction wave without any noticeable effect caudally. But in his experiment the denervation of the intestine had never been performed. As described above, one may say that as regard to the effects of intrinsic reflex upon the movements of the small intestine any consistent results have not yet been obtained. The causes of the discrepancies have remained yet undetermined, although they might partly be attributed to the difference of the species of the animal or difference of the stimuli applied. Surveying the experiments carried out by the above mentioned authors our attention was called to the fact that the muscle layer or mucous membrane has not yet separately been stimulated. A preliminary experiment revealed that the reflexes of entirely different nature were evoked depending upon the region of stimulation, muscle or mucosa. The experiments were subsequently carried out further in detail, and their results are reported in the following.

\section{METHOD}

Experimental animals used were mostly the dogs decerebrated under anesthesia with $0.5 \sim 1 \mathrm{~g}$. urethane per $\mathrm{kg}$. and $1 \sim 3 \mathrm{mg}$. morphine per $\mathrm{kg}$., or under ether anesthesia, and occasionally under electro-shock to obviate the use of narcotics. Occasionally non-decerebrated dogs anesthetized with urethane and morphine were also used. Only a few cats and rabbits were used to compare the results with those obtained from the experiments on dogs. The part of the spinal cord situated caudally from the 4 th or 5th thoracic segment was completely destroyed by insertion of the metallic probe of appropriate diameter and length. On these preparations a jejunal or ileal loop of 10 to $15 \mathrm{~cm}$. long was pulled out of the abdominal cavity, isolated from the rest of the intestine by the ligature and transection and denervated by cutting the mesenteric nerves concerned, denervation being insured by application of cocaine crystals to the transected region of the nerves. The movements of the intestinal loop were recorded by means of the balloon-method: Two balloons were thus introduced into the lumen of this denervated loop at a distance of 3 to $10 \mathrm{~cm}$. to each other and connected respectively to Marey's tambour by means of a water manometer, diastolic pressure in each balloon being maintained about 10 to $15 \mathrm{~cm} . \mathrm{H}_{2} \mathrm{O}$. The localized stimulation of the muscle or the mucosa was performed between the balloons in the following way: The mucosal surface was exposed by means of longitudinal incision along the antimesenteric border of the intestinal wall between two balloons and stimulated on the one hand mechanically by brushing with a small tooth-brush, rubbing with a clot of cotton-wool, or rapid rinsing with Tyrode's solution and on the other hand chemically by an application of a small piece of a filter paper $(3 \times 10 \mathrm{~mm}$.) moistened with $0.1 \sim 1 \mathrm{~N} \mathrm{HCl}$ solution, mustard paste, sodium chloride crystal, or half-saturated solution of copper sulphate. The muscle coats were stimulated, on the one hand, chemically by applying a small piece of filter paper $(3 \times 10 \mathrm{~mm}$.) moistened with $0.01 \sim 1 \%$ acetylcholine solution, $1 \%$ histamine, $1 \%$ pilocarpine or $10 \% \mathrm{BaCl}_{2}$ indirectly on the outer surface of serosa, or directly on the muscle coats itself after the mucosa, submucosa and serosa adhering to the muscle coats concerned were 
stripped off, and on the other hand, mechanically by stretching the muscle coats from which the mucosa and serosa were removed.

Moreover, the electric stimulation of the intestinal wall was also performed by means of repetitive stimuli supplied by a thyratron stimulator.

The room was kept at a temperature of $28^{\circ}$ to $30^{\circ} \mathrm{C}$ and humidified. Furthermore the temperature of the isolated loop was maintained by means of an electric lamp at about the body temperature of the animal.

\section{RESULTS}

\section{1) The intrinsic reflex elicited from the mucosa.}

When the mucosal surface of the denervated jejunal loop, over which the descending contraction waves are seen, is stroked lightly and repeatedly for a few seconds with a small brush, the responses are quite different whether their site of appearance is the oral side or the anal of the stimulated region: On the oral of the stimulated region the tone of the muscle is increased within a few seconds and the waves become remarkably powerful. If the stimuli are continued for some seconds more, the motility has increased more and more and finally the pulsations appear on the oral side close to the stimulated region and propagate for some distance in the oral direction, overcoming the descending contraction waves observed there before the stimulation. On the anal side of the stimulated region the tone of the muscle has decreased and the contraction waves become promptly weaker, culminating finally to the abolishment of the waves. The increase of the motility on the oral side continues for some time after cessation of the stimulation, and then subsides gradually, making way for the normal descending contraction waves, while, on the anal side, at first the tone of the muscle has gradually increased and then the normal descending contraction waves propagate here beyond the stimulated region, becoming transitorily remarkably powerful and then subsiding again gradually. An example is shown in fig. $1, A$.

The phenomena described above are also recognized by lightly rubbing the mucosal surface with a clot of cotton-wool or by rinsing the mucosal surface with squirting Tyrode's solution and pulling the mucosa is also effective. When the chemicals, $0.1 \sim 1 \mathrm{~N} \mathrm{HCl}$, half-saturated copper sulphate solution, sodium chloride crystal, or mustard paste, are applied on the mucosal surface, care being taken to avoid the mechanical stimulation of the mucosa, it results in the responses similar to those observed in cases of the mechanical stimulation; the excitatory effects on the oral side, and the inhibitory on the anal (fig. 1, B).

As regard to the stimulation of the mucosal surface of cat's small intestine a great care must be taken to avoid a stress or pulling of the intestinal wall because even such a slight stroking as those mentioned above is liable to elicit the inhibitory reflex from the muscle, of which details will be described in the next chapter. In two cases the mucosal reflex responses are similar to those observed in dogs. Stroking the mucosa elicits in rabbit's small intestine also the responses similar to those observed in dogs.

Both excitatory and inhibitory states described above have developed quite 
FIG. 1. Effects of mechanical and chemical stimulation of the jejunal mucosal surface upon the movements of the jejunum.

Dog $8 \mathrm{~kg}$., anesthetized with urethane $(0.5 \mathrm{~g} / \mathrm{kg}$.) and morphine (1 $\mathrm{mg} . / \mathrm{kg})$. The jejunum holding balloons within it is mesenterically denervated. Stimuli are applied on the mucosal surface situated between two balloons which are at a distance of $4 \mathrm{~cm}$. from each other. $A$ : Repeated stroking of the mucosal surface with a small brush elicits the excitatory state orally and the inhibitory state anally. $B$ : The same responses as in $A$ are elicited by application of $1 \mathrm{~N} \mathrm{HCl}$-solution on the mucosal surface. Upper curve: changes of intraluminal pressure in the oral balloon. $D$ and $A$ indicate respectively descending and ascend-

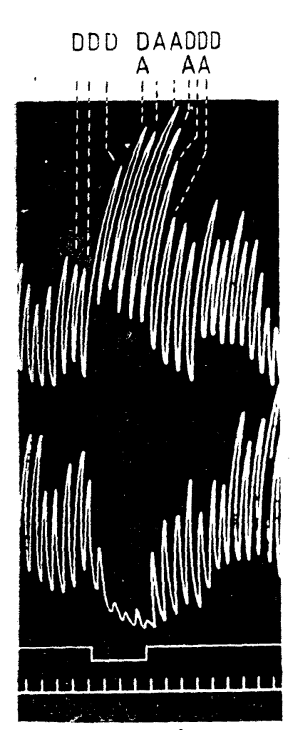

$A$

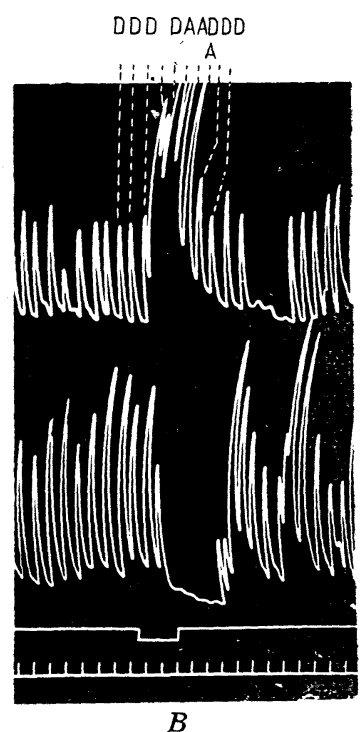

$B$ ing contraction waves. Lower curve: Changes of intraluminal pressure in the anal balloon. Signal shows the beginning and the end of mucosal stimulation. The bottom line shows the time in 6 sec. intervals.

strikingly at the region nearest to that stimulated but less remarkably the further the region is from the site of stimulation. The distance of the region where the effect is yet perceptible depends upon the strength and the duration of the stimulus. In the case of the application of $1 \mathrm{~N} \mathrm{HCl}$ for about 10 seconds the distance mentioned above is estimated about $10 \mathrm{~cm}$.

It was investigated through what path the impulses which are originated in the mucosa by its chemical or tactil stimulation reach the muscular coats to produce the responses described above. After opening the lumen of the intestine and transecting through both the mucosa and submucosa, the mucosal stimulation applied on the oral as well as anal side of the level of transection produces the same responses as seen before transection. After transecting the muscular coats at two regions $2 \sim 4 \mathrm{~cm}$. apart from each other, the stimulation of the mucosa situated between the levels of transection, however, does not elicit any responses beyond the levels of transection (fig. 2, $A, B$ ); while in the case of transecting the muscular coats at any level, the mucosal stimulation at the oral or at the anal side of the level of the transection produces respectively an excitatory as well as an inhibitory response only on the ipsilateral side, without eliciting any paired response at the contralateral side of the level of transection.

From the results described above it may be concluded that the impulses originating in the mucosa are transmitted at first through the path being involved in the muscular coats close to the stimulated region and then to the 


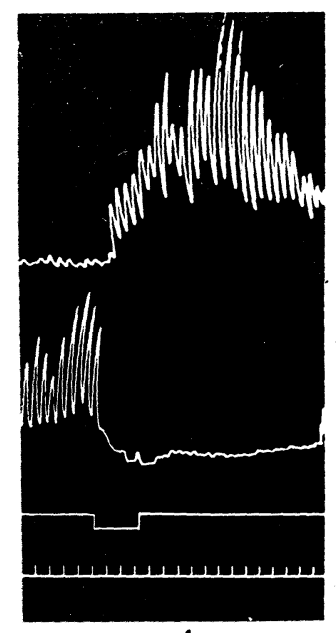

A

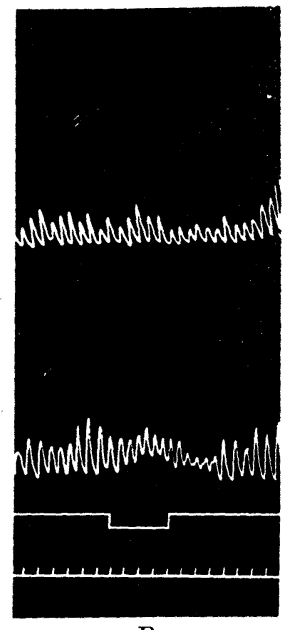

$B$

FIG. 2. Effects of mechanical stimulation of the jejunal mucosal surface upon the movements of the jejunum.

Dog $10 \mathrm{~kg}$. , decerebrated under ether anesthesia. The mucosal surface situated between oral and anal balloons is repeatedly stroked with a small brush. Distance between two balloons is $5 \mathrm{~cm}$. A: The similar responses to those seen in fig. 1, $A$ are elicited by mucosal stroking in the intact jejunum. $B$ : No responses are seen when the muscular coats are transected at the just oral as well as anal side of the stimulated region. As to the tracings the same explanation as in fig. 1 is applied.

muscular coats situated near by, while the impulses are not mediated through the mucosa and submucosa in the longitudinal direction.

When $2.5 \mathrm{mg}$. of hexamethonium bromide are intravenously administered per $\mathrm{kg}$. of body weight and additionally $7.5 \mathrm{cc}$. of $1 \%$ solution of the same chemical poured all over the surface of the isolated intestine, the mucosal stimulation does not produce any responses on the intestinal motility (fig. 3).

The intravenous administration of $3 \mathrm{mg}$. of atropine sulphate per $\mathrm{kg}$. of body weight and additional local application of $1 \%$ atropine solution do not abolish the mucosal reflex responses and the same is true in the administration of hydergine $(1.5 \mathrm{mg} / \mathrm{kg}$. intravenously and $9 \mathrm{cc}$. of $0.003 \%$ solution locally). And in the intestine, of which mesenteric nerves have been severed 6 or 12 days before the experiments, the reflex responses are obtained.

From the results described above it may be considered that the reflex pathways of the mucosal intrinsic reflexes consist of more than two neurones, of which the synapse is paralysed with hexamethonium bromide. Furthermore, it may be assumed that the impulses originated in the sensory neurone involved in Meissner's plexus and that each excitatory neurone may be in general connected with the one situated more orally while each inhibitory neurone connected with the one situated more anally; in other words, there exist a polarity in the arrangement of intrinsic motoneurones involved in Auerbach's plexus, corresponding with a polarity of the reflex responses. Such an arrangement of motoneurones has, however, remained histologically yet undetermined.

\section{2) The intrinsic reflex elicited from the muscle.}

When a small piece of filter paper moistened with acetylcholine-Tyrode's solution is placed gently on the intestinal wall situated between two balloons, the intestinal muscle contracts at the stimulated region gradually, culminating about 5 to 6 seconds after the application of chemicals in a powerful tonic con- 


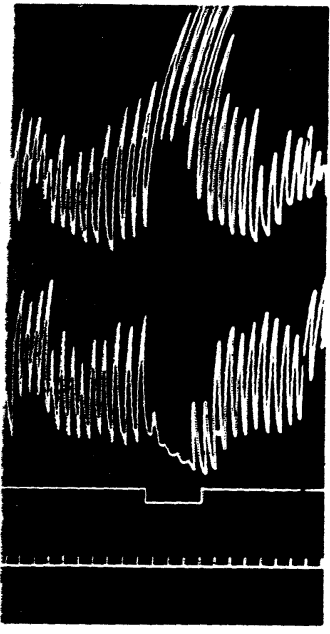

$A$

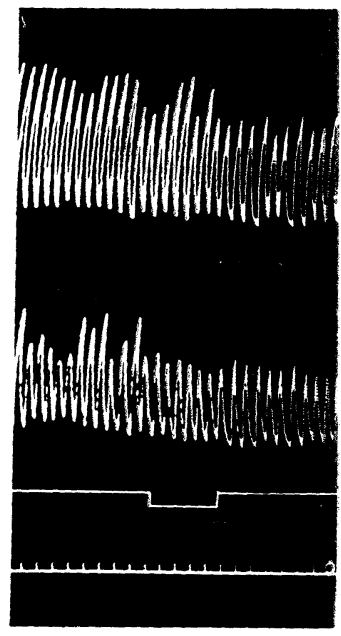

$B$

FIG. 3. Effects of administration of hexamethonium bromide upon the intrinsic reflex responses elicited by brushing of the jejunal mucosa.

Dog, $10 \mathrm{~kg}$., decerebrated under urethane $(0.5 \mathrm{~g} / \mathrm{kg}$.) and morphine (1 $\mathrm{mg} / \mathrm{kg}$.) anesthesia. Stimuli are applied on the mucosal surface situated between two balloons which are at a distance of $5 \mathrm{~cm}$. from each other. The mucosal reflex responses elicited by brushing of the mucosa, as shown in $A$, are completely abolished, as indicated in $B$, after hexamethonium bromide has been administered intravenously ( $25 \mathrm{mg}$.) and locally $(75 \mathrm{mg}$.). As to the tracings the same explanation as in fig. 1 is applicable.

striction ring. In correspondence with the events described above there occurs a gradual decrease of the amplitude of rhythmic contractions, accompanying the decrease of the muscular tone on both sides of the stimulated region, culminating occasionally in their abolishment. The inhibition on the anal side is, however, more remarkable than that on the oral as shown in fig. $4, A$.

The more concentrated the chemical solution is, the further the inhibitory effects are detectable. When $1 \%$ acetylcholine is applied, the inhibitory effects are detectable at a distance of about $10 \mathrm{~cm}$. orally and about $13 \mathrm{~cm}$. caudally. Moreover, the degree of the inhibition is highest at the region nearest to the stimulated region, decreasing gradually with a distance from the stimulated region; it may be, therefore, considered that the supposed inhibitory impulses are conducted decrementally.

When the filter paper is removed and the tonic constriction ring is repeatedly rinsed with warm Tyrode's solution, the ring begins to relax and pulsate rhythmically sooner or later, eliciting the orally as well as anally propagating waves, of which the former is more powerful than the latter. The more the ring relaxes, the weaker the pulsations become till they cease, giving place to the similar waves to those observed before the stimulation.

The application of $1 \%$ histamine, $1 \%$ pilocarpine or $10 \% \mathrm{BaCl}_{2}$ produces also similar responses to those described above. Such responses are produced not 


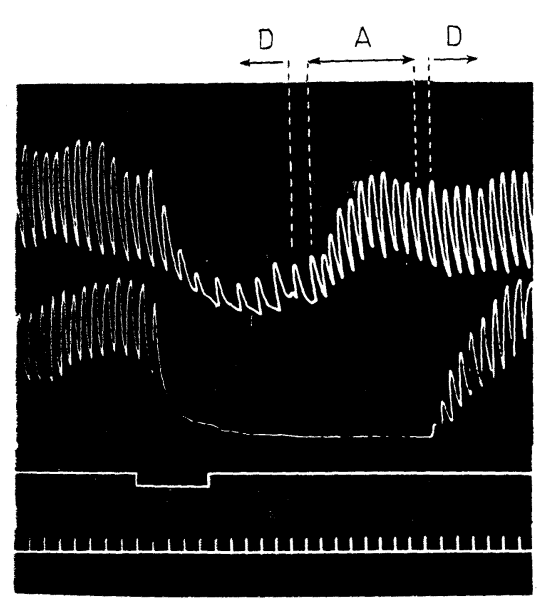

$A$

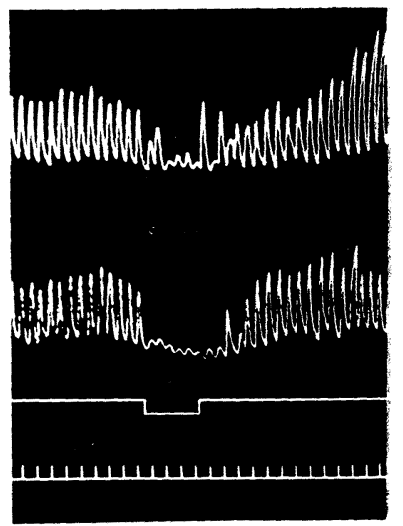

$B$

FIG. 4. Effects of chemical stimulation of the muscular coats upon the movements of the jejunum.

Dog $8 \mathrm{~kg}$., anesthetized with urethane $(1 \mathrm{~g} / \mathrm{kg}$.) and morphine $(1 \mathrm{mg} / \mathrm{kg}$.). Filter paper moistened with $1 \%$ acetylcholine is applied on the serosal surface situated between two balloons which are at a distance of $8 \mathrm{~cm}$. from each other. The inhibitory reflex responses elicited by muscular contraction $(A)$ are not abolished $(B)$ after hexamethonium bromide has been administered intravenously ( $200 \mathrm{mg}$.) and locally ( $50 \mathrm{mg}$.). Upper curve: Changes 'of intraluminal pressure in the oral balloon. Lower curve: Changes of intraluminal pressure in the anal balloon. Signal shows the beginning and the end of chemical stimulation. The bottom line shows the time in $6 \mathrm{sec}$. intervals.

only by chemical stimulation, but also by transversal or longitudinal stretching of the intestine, of which the mucosa and serosa are so completely removed that only muscular coats are remaining.

On the 6 th or 12 th day after degenerative section of the mesenteric nerves, or after administration of hydergine of hexamethonium, the inhibitory responses are evoked similarly as in the intact intestine (fig. 5). When the muscular coats are transected, the effects do not appear beyond the transected level.

From the results described above the responses resulting from the stimulation of the muscle appear to be essentially different from those from the mucosa in its mechanism.

The reflex responses produced by the electric stimulation of the intestinal wall are somewhat different from those produced by mechanical and chemical stimulation. When the moderately strong electric stimuli $(70 \mathrm{c} / \mathrm{sec} ., 10 \mathrm{~V})$ are applied on the intestinal wall to make a tonic constriction ring, there occur orally as well as anally extrasystolic conduction waves followed by inhibition of the rhythmic contractions, while in the meantime a tonically contracted ring is formed in the stimulated region (fig. $6, B$ ). The behavior of the inhibition is quite similar to that observed in cases of chemical or mechanical stimulation, whereas the extrasystolic waves are not generally observed in the mechanical 
FIG. 5. Inhibitory reflex responses elicited by stretching the jejunal wall, of which mesenteric nerves have been severed 12 days before the experiment.

Dog $7 \mathrm{~kg}$., anesthetized with urethane $(0.5 \mathrm{~g} / \mathrm{kg}$.) and morphine $(1 \mathrm{mg} / \mathrm{kg}$.). Distance between two balloons is $7 \mathrm{~cm}$. The jejunal wall is stretched transversely at the region situated $1 \mathrm{~cm}$. caudally to the oral balloon. Appearance of the muscular reflex responses remained unchanged. Upper curve: changes of intraluminal pressure in the oral balloon. Lower curve: Changes of intraluminal pressure in the anal balloon. Signal shows the beginning and the end of stretching. The bottom line shows the

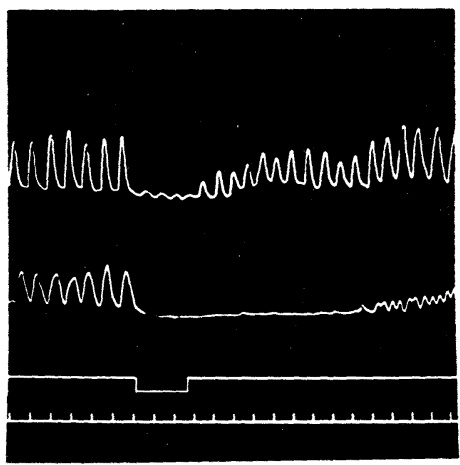
time in 6 sec. intervals.
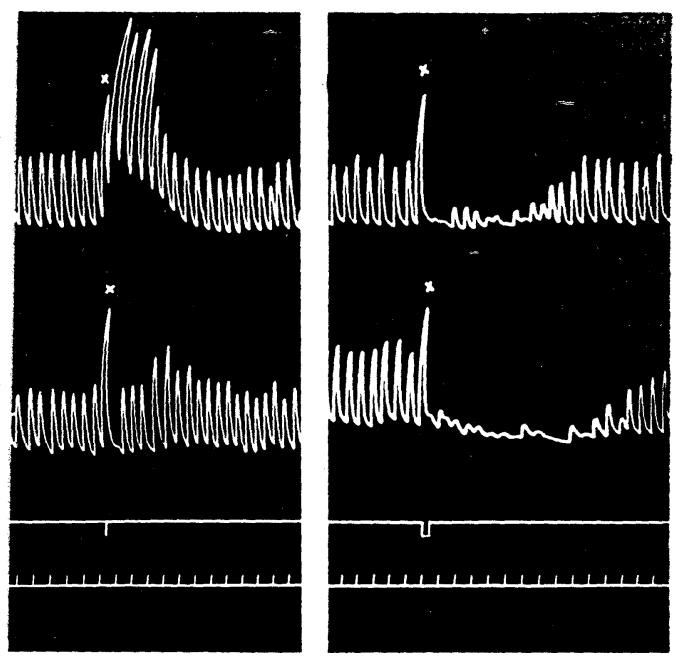

FIG. 6. Effects of electric stimulation of the jejunal wall upon the movements of the jejunum.

Dog $11 \mathrm{~kg}$., decerebrated under urethane $(0.5 \mathrm{~g} / \mathrm{kg}$. $)$ and morphine $(1 \mathrm{mg} / \mathrm{kg}$.) anesthesia. Distance between two balloons is $18 \mathrm{~cm}$. The electric stimuli are applied to the serosal surface of the jejunum situated $2 \mathrm{~cm}$. orally to anal balloon. The extrasystolic conduction waves are marked with $\times$. Strength and pulse rate of the electric stimuli applied are $10 \mathrm{~V}$ and $70 \mathrm{c} / \mathrm{sec}$. respectively. Duration of stimulation is 0.5 sec. in $A$ and $1.5 \mathrm{sec}$. in $B$. Upper curve: Changes of intraluminal pressure in the oral balloon. Lower curve: Changes of intraluminal pressure in the anal balloon. Signal shows the beginning and the end of electric stimulation. The bottom line shows the time in 6 sec. intervals. Explanations in text.

or chemical stimulation experiments. The difference in the mode of reaction of the muscle to various stimuli may have relation to the elicitation of the extrasystolic waves. The phenomena described above are likewise recognized 
after administration of hexamethonium.

The degree of inhibition has a relation with the degree of the tonic contraction produced at the stimulated region; the intestinal motility may be somewhat inhibited but never completely, when the intestinal wall is stimulated so weakly and briefly that any constriction ring is not formed. An example is shown in fig. $6, A$. In this case the weak stimuli produce the ascending and descending extrasystolic waves but the succeeding inhibitory response is hardly seen. Instead of the inhibition the stimulated region pulsate, sending out the ascending and descending waves of which the former is stronger than the latter. These responses have a similarity to those obtained by strong stimulation of the mucosa. The elicitation of the responses may be, therefore, due to the direct stimulation of the excitatory and inhibitory neurones concerned with the mucosal reflex. It is noteworthy that the results above mentioned are furthermore fairly consistent with those obtained in the pinching-experiments carried out by Hukuhara et al. In addition we refer to some noteworthy facts: When the wall of the innervated small intestine is distended, both the intrinsic (muscular) and extrinsic reflexes are able to be elicited simultaneously but with a different threshold of stimulus, being far lower in the former than in the latter.

\section{DISCUSSION}

Regarding the intrinsic intestinal reflex effects the consistent results have not been obtained by previous authors. It may be presumed that effects obtained by stimulation of the wall of the small intestine consist of those of various origins. According to the results reported in this paper, the origins of the responses may be indeed classified as follows:

(1) The intrinsic reflex response elicited by mechanical or chemical stimulation of the intestinal mucosa. The mucosal stimulation causes the remarkable excitatory state of the intestinal muscle orally, and the inhibitory anally.

(2) The intrinsic reflex response produced by mechanical or chemical stimulation of the muscle. The reflex elicited by stimulation of the receptor involved in the intestinal muscle, producing an inhibitory state of the muscle both on the anal and oral sides; the degree of inhibition is higher on the anal than that on the oral.

(3) The direct responses of the intestinal muscle to the mechanical or chemical stimulation. The muscular stimulation is capable of eliciting the pulsations at the stimulated region, which result in the propagated waves on both sides of the region.

(4) The responses elicited by direct stimulation of the intramuscular motoneurones (e.g., Auerbach's plexus); these responses are analogous to those elicited by mucosal reflex.

It may be considered that the intricated responses as obtained by previous authors resulted from the combination of all or some of the responses mentioned above. The stimuli, for example, pinching or longitudinal as well as transversal stretching of the intestinal wall $(4,5,7,9,13,15,17)$, insertion of the bolus into the intestinal lumen $(4,5,8,13)$, distension of the intestinal wall by insertion of the balloon $(5,16,21)$, application of $\mathrm{NaCl}$-crystal on the 
serosal surface or electric stimulation of the intestinal wall $(2,3,4,5,7,17,19)$ would be capable of producing the mixed responses of different origin. Bozler (7) and Borchardt (6) tried to stimulate the mucosa only, but their results do not agree with ours in that they could not observe the inhibitory effect anally, so that Bozler doubt whether the inhibition should be considered as a part of the so-called myenteric reflex effects or not. According to our experience it happens often so, when the intestine is relaxed and motionless. In rabbits Bozler could not obtained orally the excitatory effect expected by stroking of the mucosa by a blunt instrument, while we could, in contrast with his results, also ascertain the remarkable excitatory effect in these animals. The discrepancy of the results may be dependent upon the difference of the experimental conditions. In agreement with Hukuhara's opinion we believe that movements of the small intestine consist of essentially a kind of the rhythmic contraction wave, although they show apparently manifold aspects, and that the extrinsic and intrinsic reflexes elicited from the muscle and mucosa contribute to regulate the contraction waves. The extrinsic reflex exerts an inhibitory response equally all over the small intestine, while the intrinsic reflexes consist of the mucosal and muscular reflexes, showing especially in the former a characteristic polarity of responses. Now the question how the normal course of the intestinal movements is affected by the intrinsic reflexes will be taken up.

In the duodenum the contraction waves originate rhythmically in the uppermost part of the duodenum, the pace maker region (Hukuhara). The intestinal contents are little by little transported by each wave to the anal direction, rubbing the mucosal surface. Rubbing stimulates the receptors involved in the mucosa to elicit the mucosal reflex, so that the duodenal motility is excited orally and inhibited anally. Such a circumstance would possibly prevent the origination of the contraction waves on the region situated more anally than that situated more nearly to the pace maker, promoting the dominance of the motility of the region situated more orally than that situated more anally. The inhibitory state may be further more an important factor capable of causing the decrement of the propagated contraction wave. The same argument may be valid for the other region of the small intestine. It may be said that the polarity or the gradient of the small intestine is related not only with the gradient (1) of the muscular excitability from above downwards, but also with the nervous factors as described above.

When the gastric contents are pushed into the duodenum by the peristalsis of the stomach, one or two successive periodic contraction waves of the duodenum become exceedingly powerful. Such contraction waves were named "peristalsis" by Hukuhara, and in the course of the propagation of waves the extrinsic and intrinsic reflexes would be necessarily evoked powerfully. The integrated effect is orally an increase of the strength of the waves, while it is anally a decrease of that of the waves, which fact makes easier to receive the chyme transported.

If the excitability happens to rise locally to an abnormaly high degree in any region of the small intestine, the intrinsic reflexes would be provoked quite markedly. In this case the excitability would be raised at the region concerned 
so highly that lastly the ascending contraction waves (anti-peristalsis) are rhythmically originated from there. The ileus or the inflammation in the intestine may be offered as an example.

Under normal conditions the chyme in the small intestine is in general semiliquid, without any boluses. The solid materials are, however, often introduced experimentally into the lumen. The phenomena observed in such a case can be explained as follows: When a solid material (bolus) is introduced into the lumen, the intestinal wall is stimulated to evoke the reflexes described above. As the result of the integrative effect of the reflexes there occur the excitatory state orally and the inhibitory anally. Consequently the succeeding waves are intensified orally and weakened anally. If the bolus is too large to be forced anally by the first and second waves, the excitatory state is summated orally in the course of the passage of the successively propagated waves over the bolus, and the contraction waves are thus intensified more and more, culminating to the degree of strength capable of transporting the bolus to the anal direction. Accordng to Bozler's postulation, such an advancing front of strong rhythmic activity should be named peristalsis, discriminating it from a single wave of contraction. According to our mode of explanations described above, it would be, however, unnecessary to discriminate a pattern of intestinal movements, peristalsis in Bozler's sense from other patterns.

\section{SUMMARY}

In dogs, cats and rabbits decerebrated under anesthesia or nonanesthesia, the intrinsic reflexes were studied in the denervated small intestine. The results are summarized as follows:

(1) It was found that the intrinsic reflexes of the small intestine were consisted of two different kinds of the reflexes, of which the one was elicited from the mucosa, while the other from the muscle:

(a) When the surface of the mucosa was mechanically rubbed with brush or cotton-wool, or stimulated chemically with 0.1 normal solution of $\mathrm{HCl}$, halfsaturated copper sulphate solution, mustard paste or crystals of sodium chloride, the excitatory state was elicited on the oral side of the stimulated region, giving rise to an increase in the strength of normal rhythmic contractions, while the inhibitory state on the anal side, eliciting a decrease in the strength of rhythmic contraction waves. This excitatory state might be occasionally so exceedingly enhanced that the ascending waves are elicited from the stimulated region. The reflex responses were elicited after the degenerative section of the mesenteric nerves concerned, while they were abolished after administration of hexamethonium.

(b) When the muscular coats were mechanically stretched or chemically stimulated, i.e., with acetylcholine, histamine, pilocarpine or $\mathrm{BaCl}_{2}$ the rhythmic contraction waves were inhibited on both sides of the stimulated region. The administration of hexamethonium as well as the degenerative section of the mesenteric nerves concerned had no influence upon the reflex responses.

(2) The discrepancies among the results obtained by previous authors would be chiefly due to the mode of stimulation, having the tendency of both the 
mucosal and muscular reflexes being invoked at the same time. Furthermore it was observed that the reflexes described above might play an important role to realize the polarity observed on the motility of the small intestine.

\section{REFERENCES}

1. Alvarez, W. C. An introduction to gastro-enterology. 4th edition. New York: Hoeber, 1948.

2. Alvarez, W. C. And Starkweather, E. Conduction in the small intestine. Am. J. Physiol. 50: 252, 1919.

3. Alvarez, W. C. AND Hosor, K. Conduction in different parts of the small intestine. Am. J. Physiol. 94: 448, 1930.

4. BAyliss, W. M. And Staling, E. H. The movements and innervation of the small intestine. J. Physiol. 24: 99, 1899.

5. BAyliss, W. M. AND STARLING, E. H. The movements and innervation of the small intestine. J. Physiol. 26: 125, 1901.

6. BORCHARDT, W. Gibt es nervöse Chemorezeptoren in der Dünndarmschleimhaut? Pflüger's Arch. 215: 402, 1927.

7. Bozler, E. Myenteric reflex. Am. J. Physiol. 157: 329, 1949.

8. Bozler, E. Reflex peristalsis of the intestine. Am. J. Physiol. 157: 338, 1949.

9. FleIsCH, A. UND V. WYSS, W. H. Zur Kenntnis der visceralen Tiefensensibilität. Pfï̈ger's Arch. 200: 290, 1923.

10. Herrin, R. C. AND MEEK, W. J. Afferent nerves excited by intestinal distension. Am. J. Physiol. 144: 720, 1945.

11. Hukuhara, T. Die normale Dünndarmbewegung (Mit Hilfe der Bauchfenstermethode und Kinematographie). Pfï̈ger's Arch. 226: 518, 1930-1931.

12. Hukuhara, T. Weitere Studien über die normale Dünndarmbewegung. Pfüger's Arch. 235: 164, 1934.

13. Hukuhara, T., Masuda, K. AND Kinose, S. Über das “Gesetz des Darmes”. Pfiüger's Arch. 237: 619, 1936.

14. Hukuhara, T. AND Yokoyama, S. Kritik an der Trendelenburgschen Theorie über die Dünndarmperistaltik. Jap. J. med. Sci. Biophysics 8: 19, 1942.

15. Langley, J. N. AND Magnus, R. Some observations of the movements of the intestine before and after degenerative section of the mesenteric nerves. J. Physiol. 33: 34, 1905-1906.

16. LÜDERITZ, C. Experimentelle Untersuchungen über die Entstehung der Darmperistaltik. Virchow's Arch. 118: 19, 1889.

17. Magnus, R. Versuche am überlebenden Dünndarm von S̈augethieren. Pfïger's Arch. 102: $132,1904$.

18. Morin, G. ET VIAL, J. Sur les voies et les centres du réfiexe inhibiteur intestinointestinal. Compt. rend. Soc. Biol. 116: 537, 1934.

19. Nothnagel, H. Zur chemischen Reizung der glatten Muskeln; zugleich als Beitrag zur Physiologie des Darmes. Virchow's Arch. 88: 1, 1882.

20. Peterson, C. G. AND Youmans, W. B. The intestino-intestinal inhibitory reflex; threshold variations, sensitization and summation. Am. J. Physiol. 143: 407, 1945.

21. Youmans, W. B., MEEK, W. J. AND Herrin, R. C. Extrinsic and intrinsic pathways concerned with intestinal inhibition during intestinal distention. Am. J. Physiol.124: 470, 1938.

22. Youmans, W. B. Effect of denervation of intestine on its motor responses at a site of distension. Proc. Soc. Exp. Biol. and Med. 45: 420, 1904.

23. Youmans, W. B., Kartens, A. I. And Aumann, K. W. Nervous pathways for the reflex regulation of intestinal pressure. Am. J. Physiol. 135: 619, 1942. 